
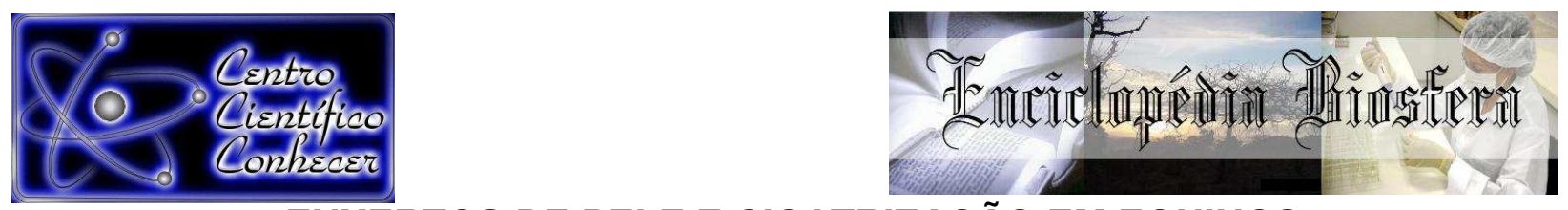

\title{
ENXERTOS DE PELE E CICATRIZAÇÃO EM EQUINOS
}

Ana Carolina Barros da Rosa Pedroso1; Letícia Hirata Mendes²; Plínio Azevedo Coelho2; Veridiana Maria Brianezi Dignani de Moura ${ }^{3}$; Luciana Ramos Gaston Brandstetter $^{4}$

\footnotetext{
'Médica Veterinária, mestranda do Programa de Pós-graduação em Ciência Animal/Escola de Veterinária e Zootecnia, Universidade Federal de Goiás, Goiânia, Goiás, Brasil (anacarolinapedroso@ymail.com)

²Acadêmicos em Medicina Veterinária, Universidade Federal de Goiás, Goiânia, Goiás, Brasil

${ }^{3}$ Professora Doutora do Setor de Patologia Animal, Universidade Federal de Goiás, Goiânia, Goiás, Brasil

${ }^{4}$ Professora Doutora do Setor de Clínica e Cirurgia, Universidade Federal de Goiás, Goiânia, Goiás, Brasil
}

\section{Recebido em: 08/04/2017 - Aprovado em: 10/06/2017 - Publicado em: 20/06/2017 DOI: 10.18677/EnciBio_2017A46}

\begin{abstract}
RESUMO
As feridas de pele são muito comuns na clínica de equinos. Os ferimentos localizados em regiões distais dos membros dos equinos são considerados particularmente complicados no que se refere à reparação tecidual. O processo de cicatrização ou de reparo é uma tentativa do organismo restaurar a integridade anatômica ou funcional do tecido lesionado e, didaticamente, pode ser dividido em três fases: fase inflamatória, fase fibroblástica e fase de maturação e remodelamento. Existem vários fatores que afetam o processo de cicatrização na espécie equina. Alguns tratamentos, produtos e procedimentos têm demonstrado benefício nesse processo. Os enxertos de pele são uma boa alternativa, especialmente para feridas em membros distais. $O$ seu uso pode melhorar o resultado final da cicatrização, tanto em relação ao tempo, quanto em relação aos resultados cosméticos e funcionais.
\end{abstract}

PALAVRAS-CHAVE: cavalos, feridas, inflamação, lesão, pinch, punch

\section{EQUINE SKIN GRAFTS AND WOUND HEALING}

\begin{abstract}
Skin wounds are very common in the equine practice. Wounds located in distal limbs are considered particularly complicated in regard to tissue repair. The process of healing or repair is an body attempt to restore the anatomical or functional integrity of the injured tissue and can be divided into three phases: inflammatory phase, fibroblast phase and maturation and remodeling phase. There are several factors that affect the healing process in the equine species. Some treatments, products and procedures have shown benefit in this process. Skin grafts are a good alternative,
\end{abstract}


especially for wounds on distal limbs. Its use can improve the final healing result, both in terms of time and in relation to cosmetic and functional results.

KEYWORDS: horse, inflammation, lesion, pinch, punch, wound

\section{INTRODUÇÃO}

As feridas de pele são muito comuns na clínica de equinos e representam um desafio para os médicos veterinários e proprietários desses animais, pois, muitas vezes, resultam em tratamentos muito longos e de alto custo (THEORET, 2005). Para estabelecer um tratamento adequado, o veterinário deve ter um bom conhecimento a respeito da anatomia e do processo de cicatrização, para que, dessa forma, saiba reconhecer precocemente as eventuais complicações (CASTON, 2012).

Os ferimentos localizados em regiões distais dos membros dos equinos são considerados particularmente complicados no que se refere à reparação tecidual. Isso acontece por diversos fatores, tais como a escassez de pele, o baixo suprimento sanguíneo, a presença de grande comprometimento tecidual, o alto risco de contaminação e o atraso na cicatrização. Além disso, existe uma predisposição ao desenvolvimento de tecido de granulação exuberante e fibrose na região distal dos membros dos equinos, o que pode ocasionar o desenvolvimento de feridas crônicas de difícil cicatrização (WILMINK \& WEEREN, 2005).

O crescente número de animais e a importância econômica relevante da criação de equinos no Brasil, além das perdas representadas pelos ferimentos cutâneos nesta espécie, denotam a importância do desenvolvimento de novos tratamentos, economicamente viáveis, para promover a cicatrização tecidual. Os enxertos de pele são opções viáveis quando uma ferida não pode ser fechada cirurgicamente, ou excede a capacidade de cicatrização pela contração e epitelização. A enxertia de uma ferida granulomatosa é considerada um tratamento de custo-benefício favorável e de fácil execução (DAHLGREN, 2009).

\section{CICATRIZAÇÃO}

O processo de cicatrização ou de reparo é uma tentativa do organismo restaurar a integridade anatômica ou funcional do tecido lesionado. Esse processo se caracteriza por uma complexa cascata de eventos bioquímicos e celulares sequenciados, em resposta à lesão tecidual e que são precisamente controlados, tendo como resultado final uma cicatriz de tecido conjuntivo. Quando há um descontrole na sequência ou no equilíbrio desses eventos, a consequência é uma cicatriz de tecido conjuntivo exuberante, produzida por uma quantidade excessiva de colágeno, conhecida como queloide. Didaticamente, o processo de reparo pode ser dividido em três fases, mas os eventos e elementos de cada uma delas se sobrepõem. São elas: fase inflamatória, fase fibroblástica e fase de maturação e remodelamento (JONES et al., 2000).

\section{Fase inflamatória}

O evento inicial em qualquer ferida é vascular. A vasoconstrição ocorre imediatamente, em resposta à dor e ao trauma, para controlar a hemorragia e dura de cinco a dez minutos. A vasodilatação ocorre em seguida à vasoconstrição, juntamente com o aumento da permeabilidade capilar. Esses dois eventos em conjunto permitem que componentes sanguíneos celulares e não celulares entrem na ferida, através da diapedese, formando um trombo fibrocelular. A fibrina se 
acumula rapidamente, servindo como uma barreira para proteger o tecido subcutâneo exposto (BAXTER, 1999).

As plaquetas extravasadas aderem ao colágeno no espaço perivascular e são ativadas, liberando o conteúdo dos seus grânulos: citocinas e fatores de crescimento, que estimulam a migração leucocitária (THEORET, 2005). O fibrinogênio, a fibronectina, o fator de von Willebrand e a trombospondina, também liberados pelos grânulos plaquetários, se somam à massa agregada de plaquetas e fibrina, fortalecendo a nova matriz extracelular provisória. O sistema fibrinolítico degrada a fibrina e os produtos dessa degradação também são quimiotáticos para células de defesa (JONES et al., 2000).

Os neutrófilos, que são a primeira linha de defesa do organismo, têm a função principal de fagocitar e matar bactérias e a sua concentração na ferida diminui em alguns dias, caso não haja contaminação e colonização bacteriana. Os macrófagos começam a se acumular na ferida entre dois e cinco dias após a lesão e esse influxo é primordial na indução dos mecanismos de reparo. Essas células auxiliam os neutrófilos na fagocitose de microorganimos e debris teciduais, além de removerem os neutrófilos exauridos e, assim como as plaquetas, liberarem fatores de crescimento e citocinas, responsáveis pela manutenção da reação inflamatória e pela iniciação, maturação e controle do processo de cura (JONES et al., 2000). No processo de cicatrização normal, os macrófagos permanecem na ferida de dias a semanas (SINGER \& CLARK, 1999).

O resultado final do estágio inflamatório é o acúmulo de um exsudato inflamatório, que leva aos quatro sinais cardinais da inflamação: calor, dor, tumor e rubor. A intensidade e a duração dessa resposta dependem da intensidade da lesão, podendo durar de seis a 12 horas (BAXTER, 1999). A inflamação é essencial à resolução normal da ferida, porém, quando não se resolve dentro do tempo esperado, pode contribuir para o desenvolvimento de fibrose e cicatriz excessiva. Para a inflamação cessar, os estímulos devem ser inativados e a permeabilidade vascular normal deve ser reestabelecida para impedir a passagem contínua de células sanguíneas para o espaço extravascular. Da mesma forma, as atividades secretórias das células inflamatórias devem ser interrompidas, os receptores dos mediadores devem ser menos expressos ou fatores inibitórios devem ser produzidos e, finalmente, neutrófilos e macrófagos devem ser destruídos e removidos no leito da ferida (THEORET, 2005).

\section{Fase fibroblástica}

Essa fase é caracterizada por fibroplasia, angiogênese, reepitelização e contração da ferida (BAXTER, 1999). A ativação das plaquetas e dos macrófagos leva à liberação de fatores de crescimento específicos, que desempenham papel crucial na migração e diferenciação de células necessárias para a formação do tecido de granulação. A matriz extracelular começa a ser substituída por tecido conjuntivo mais forte e elástico. A cicatriz de tecido conjuntivo maduro tem 0 colágeno como principal componente e, nessa fase, os fibroblastos são recrutados para produzir essa proteína (JONES et al., 2000).

A fibroplasia inicia-se pela formação do tecido de granulação, que se caracteriza por uma matriz frouxa de colágeno, fibronectina e ácido hialurônico, que contém macrófagos, fibroblastos e vasos recém-formados (JONES et al., 2000). O estroma granular e vermelho, característico desse tecido, começa a invadir o defeito aproximadamente cinco dias após a injúria com a função de proteção contra infecções e para fornecer uma superfície por onde a qual as células epiteliais 
possam migrar (THEORET, 2005). A angiogênese ocorre concomitantemente à fibroplasia e é secundária à diferenciação das células endoteliais migratórias (JONES et al., 2000). Essa fase envolve a formação de novos vasos sanguíneos a partir de vasos pré-existentes (LI et al.,2003).

Os fibroblastos presentes no tecido de granulação depositam grandes quantidades de fibronectina na ferida, que é substrato necessário para a fixação celular. Além da fibronectina, o ácido hialurônico também é um componente importante nessa fase do reparo, pois causa o enfraquecimento da fixação das células no substrato. Dessa forma, o tecido de granulação forma um microambiente eficiente para a movimentação das células, possibilitando a sua fixação, desalojamento e refixação e, consequentemente, intensa migração celular. À medida que o processo de cura evolui, o ácido hialurônico vai sendo substituído por proteoglicanos, que favorecem a fixação e imobilidade das células. Essas células se diferenciam em tipos mais maduros e funcionais e os fibroblastos dão início à formação do colágeno (JONES et al., 2000).

A hipóxia é prejudicial ao processo de formação do colágeno e o oxigênio deve ser obtido a partir da nova vasculatura sanguínea que provém das margens da ferida. É necessário que haja um equilíbrio entre a hipóxia que impulsiona a migração celular e a angiogênese em seu início e a alta demanda de oxigênio para a síntese do colágeno. Os proteoglicanos e a fibronectina são cada vez mais substituídos pelo colágeno recém-formado, que é o principal componente da cicatriz. Nessa mesma fase, alguns fibroblastos se diferenciam em miofibroblastos, que são as células contráteis responsáveis pela contração da ferida (JONES et al., 2000).

A reepitelização, estimulada por fatores de crescimento específicos, é iniciada em algumas horas após a lesão cutânea e se dá pela migração das células epiteliais da margem da ferida, que sofrem alterações fenotípicas específicas e adquirem a capacidade de se movimentar lateralmente. Essa migração ocorre com maior rapidez quando a superfície da ferida está umedecida e bem oxigenada, o que se torna um desafio para o clínico, que deve lançar mão de curativos que sejam permeáveis ao oxigênio, mas que não impeçam o ressecamento da ferida (JONES et al., 2000).

\section{Maturação e remodelamento}

O estágio final do processo de cicatrização é a maturação da cicatriz de colágeno formada durante a fase fibroblástica. Esse estágio é caracterizado pela diminuição na vascularização da ferida e no número de fibroblastos e macrófagos (BAXTER, 1999). O processo de remodelamento envolve contínua produção, digestão, agregação e orientação das fibras e fibrilas de colágeno da ferida, que são depositadas sobre o "gabarito" de fibronectina de modo aleatório inicialmente. Essas fibras são posteriormente digeridas pela colagenase, que é produzida por vários tipos celulares (leucócitos, macrófagos, fibroblastos e células endoteliais) independentemente da presença de oxigênio, e depositadas novamente de modo similar àquelas do tecido adjacente não afetado. Feridas com oxigenação inadequada têm maior produção de colagenase e dão origem à cicatriz menor e mais fraca. Dessa forma, deve existir um equilíbrio entre a produção e a degradação do colágeno, para que a cicatriz não cresça de tamanho ou não fique muito pequena. A maturação é a fase final do processo de reparo, que pode durar de meses a anos. A cicatriz cutânea completamente madura tem apenas $70 \%$ da resistência da pele normal (JONES et al., 2000). 
A cura de uma ferida é um processo complexo e que depende de interações entre células, fatores de crescimento, componentes da matriz extracelular e oxigênio. $O$ sucesso desse processo está diretamente ligado ao equilíbrio entre essas interações, às relações dinâmicas entre os seus componentes e à sobreposição significativa entre as fases do reparo (JONES et al., 2000).

\section{FATORES QUE RETARDAM A CICATRIZAÇÃO EM EQUINOS}

Existem vários fatores que afetam o processo de cicatrização na espécie equina. $O$ conhecimento a respeito desses fatores é importante para que seja estabelecido o melhor tratamento, visando acelerar o fechamento da ferida de forma adequada. $\mathrm{O}$ grau de contaminação e a presença de tecido necrótico ou corpos estranhos são fatores importantes na evolução do processo de cicatrização e na escolha do melhor tratamento. A maioria das feridas é colonizada por um nível normal de bactérias, que são importantes para a resposta imune e resposta inflamatória (EDWARDS \& HARDING, 2004), porém quando esse nível ultrapassa o aceitável, a ferida torna-se infeccionada e é recomendada a realização de cultura bacteriana e antibiograma para a escolha do antibiótico mais adequado. A presença de corpos estranhos como madeira, metal, implantes cirúrgicos e fios de sutura é fonte de infecção e irritação, assim como a presença de tecido necrótico, que devem ser investigadas naquelas feridas que não cicatrizam (GIFT \& DEBOWES, 1989).

A localização da lesão também afeta diretamente 0 processo de cicatrização. As feridas localizadas nos membros distais dos equinos possuem particularidades no reparo. A cicatrização é mais lenta nessa região devido a fatores como inflamação persistente e presença de pele com maior tensão e menor suprimento sanguíneo, o que leva a uma parada precoce na retração da ferida (JACOBS et al., 1984). Além disso, a ausência de cobertura muscular, a alta mobilidade e o alto grau de contaminação, devido à proximidade com o solo, também contribuem para o atraso na cicatrização (COCHRANE et al., 2003). Feridas localizadas em áreas com grande mobilidade têm maior predisposição ao desenvolvimento de inflamação crônica devido ao rompimento de novos capilares, de depósitos de colágeno e do epitélio novo e frágil. A grande tensão da pele na região dos membros distais altera o resultado cosmético da cicatriz, aumenta a reação inflamatória e pode comprometer os tecidos vizinhos, além de contribuir na diminuição do fluxo sanguíneo. Por sua vez, o suprimento sanguíneo insuficiente no leito da ferida aumenta o risco de infecção e diminui a taxa de cura (BERTONE, 1989).

Outro importante fator que afeta a cicatrização em equinos e que está relacionado à localização da lesão é o envolvimento de estruturas sinoviais, tendíneas e ligamentares. Feridas que estão próximas ou que envolvem as estruturas sinoviais necessitam de muito rigor quanto à antissepsia e aquelas que comprometem tendões e ligamentos geralmente requerem imobilização. Quando há exposição óssea, o que é muito comum nas lacerações que acometem os membros distais, pode ocorrer a formação de sequestro ósseo. Essa formação pode demorar semanas para aparecer e geralmente acontece abaixo de uma cobertura de tecido de granulação não-saudável, fazendo com que seja difícil a sua identificação (FIGURA 1). Quando há a suspeita de sequestro ósseo, é recomendada a realização de exame radiográfico (KNOTTENBELT, 2003). 


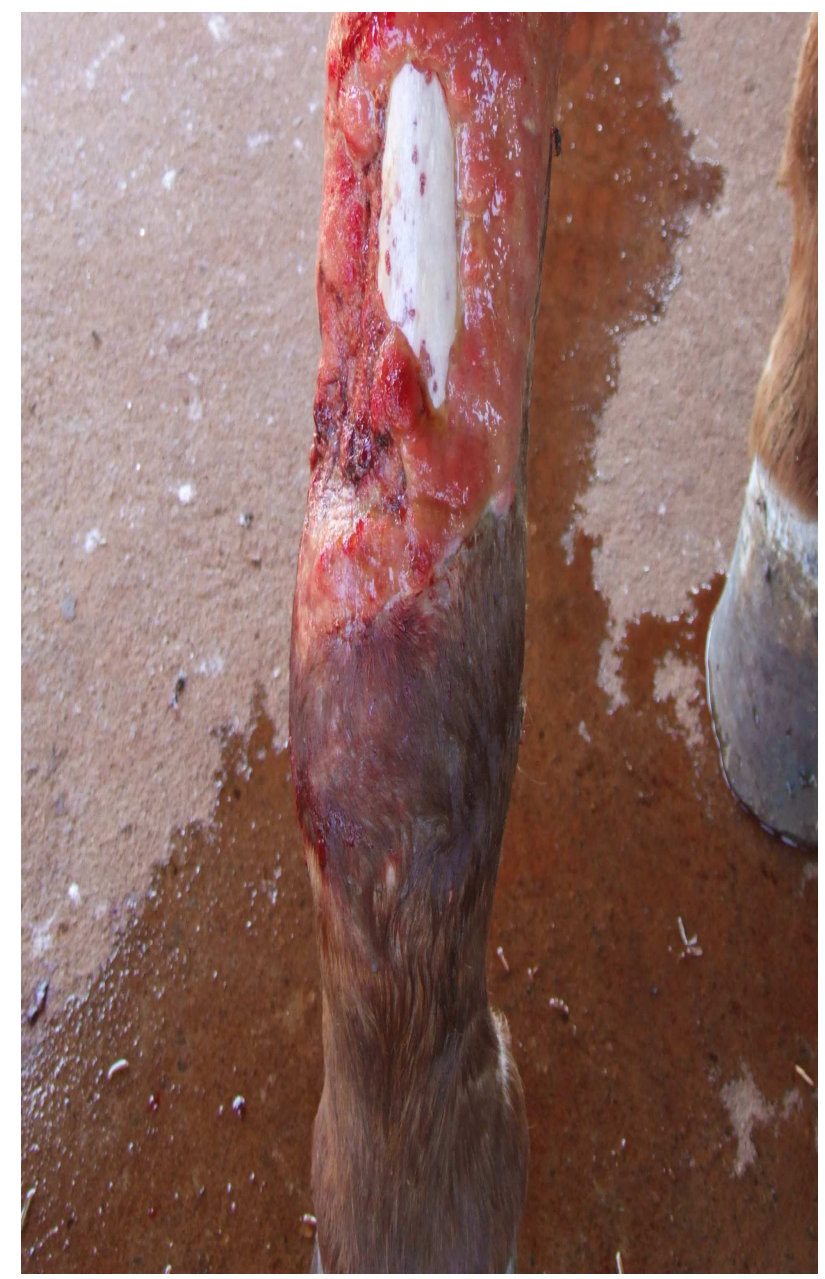

FIGURA 1 - Laceração em região dorsal da canela de membro pélvico direito em equino, com formação de sequestro ósseo.

Fonte: Setor de Grandes Animais, HV/UFG.

A realização de tratamentos prévios também deve ser levada em consideração, uma vez que podem influenciar negativamente a cicatrização por diminuir a proliferação celular e a resposta imune (MOY, 1993). O peróxido de hidrogênio e as soluções concentradas de iodopovidona possuem efeito citotóxico em fibroblastos e queratinócitos humanos e já se relatou atraso cicatrização em modelos animais (RODEHEAVER et al., 1982). A aplicação tópica de corticosteroides também retarda a cicatrização por meio da diminuição da proliferação de fibroblastos e inibição da síntese proteica (BODNER et al., 1991), mas é benéfica quando há o desenvolvimento de tecido de granulação exuberante.

Por fim, fatores econômicos, como custos do tratamento, e fatores inerentes ao temperamento, saúde e estado nutricional do animal também interferem na cicatrização. A deficiência no consumo de proteína diminui a proliferação de fibroblastos, a angiogênese, a síntese de colágeno e proteoglicanos e 0 remodelamento do colágeno (STOTTS \& WIPKE-TEVIS, 2001). A vitamina A interfere positivamente na epitelização e a vitamina $\mathrm{C}$, em conjunto com o ferro, tem ação na produção de colágeno. O zinco tem papel significativo na síntese de tecido 
de granulação e tecido cicatricial, além de estimular a epitelização (TARNOW et al., 1994).

\section{MANEJO DOS FERIMENTOS CUTÂNEOS EM EQUINOS}

A abordagem inicial dos ferimentos cutâneos consiste em uma exploração profunda do local da lesão, de forma a determinar quais as estruturas envolvidas. Danos a estruturas como cavidades torácica e abdominal, grandes vasos, estruturas sinoviais, tendões flexores e ligamento suspensório do boleto aumentam muito a gravidade da lesão e complicam o tratamento (CASTON, 2012).

Após a triagem da ferida, realiza-se uma limpeza profunda com soluções antissépticas e o enxague deve ser feito com fluidos isotônicos em grande volume, o que auxilia na diminuição da contaminação local. Quando a ferida estiver limpa, é feito o debridamento para retirada da contaminação mais profunda. Os flaps de pele não devem ser retirados até que se tenha certeza que não são mais viáveis, especialmente na cabeça e nos membros distais, devido à escassez de pele móvel nesses locais (THEORET, 2008).

Se possível, depois da limpeza e do debridamento da ferida, deve-se realizar a dermorrafia ou a máxima aproximação de suas bordas. Mesmo nos casos em que haja suspeita de deiscência ou necrose dos flaps, a sutura pode ser feita, ainda que parcialmente, pois ajudará a manter os tecidos no lugar, proteger as estruturas envolvidas e minimizar a contaminação. A colocação de um dreno pode ser necessária em feridas muito contaminadas ou com espaço morto em excesso (WISON, 2008). Por fim, a colocação de uma bandagem adequada é de extrema importância para redução do edema e proteção contra contaminação (CASTON, 2012).

Alguns tratamentos, produtos e procedimentos têm demonstrado benefício no processo de cicatrização das feridas de equinos, mas o grau desse benefício depende muito das características da lesão, da sua localização no corpo do animal e do estágio em que ela se encontra no início do tratamento (DART, 2005). Existe uma infinidade de produtos cicatrizantes disponíveis no mercado e cabe ao médico veterinário analisar a sua composição e optar pelo mais adequado, pois muitos deles possuem substâncias irritantes que podem trazer mais prejuízos do que benefícios (WILMINK, 2004). Além disso, é muito importante que o médico veterinário reconheça a fase do processo de cicatrização em que se encontra a ferida, antes de optar pelo tratamento mais apropriado (THEORET, 2008).

A resposta inflamatória é mais lenta e prolongada na espécie equina. Essa característica leva ao desenvolvimento de feridas crônicas, principalmente aquelas localizadas em membros. Sendo assim, o tratamento nessa fase tem o objetivo de aumentar a intensidade dessa resposta, diminuir a sua duração e deve focar em três questões principais: a identificação da causa do atraso ou da obstrução ao reparo, a remoção dessa causa e a criação de um ambiente favorável na ferida (THEORET, 2008).

O uso de anti-inflamatórios não-esteroidais (AINEs) é controverso nessa fase, pois pode exercer efeitos adversos na migração leucocitária e na taxa de infecção, o que pode atrasar ainda mais o reparo. Dessa forma, os AINEs devem ser usados com cautela e são mais recomendados, em doses baixas, nos casos de claudicação severa ou de edemas extensos que prejudiquem a circulação local (WILMINK, 2004). Em equinos, diferentemente do que em outras espécies, a manutenção de umidade no ambiente da ferida pode ser prejudicial ao processo de cicatrização. Essa umidade é mantida pela colocação de curativos oclusivos, que 
podem levar ao acúmulo de exsudato e ao crescimento de tecido de granulação exuberante. É recomendado que seja feita a utilização desse tipo de curativo somente até o início da fibroplasia, para evitar essa complicação (HOWARD, 1993).

Já na fase fibroblástica, o objetivo do tratamento deve ser estimular a proliferação e a migração celular necessárias para que haja angiogênese, fibroplasia e epitelização, enquanto restringe a atividade sintética dos fibroblastos para que não haja crescimento excessivo de componentes da matriz extracelular. Assim que a resposta inflamatória começa a se resolver, 0 uso de agentes quimiotáticos específicos para células mesenquimais é benéfico, além do fornecimento de suporte para a migração celular (THEORET, 2008). Esse tipo de terapia é baseado principalmente em citocinas e em fatores de crescimento, que são conhecidos por estimular a ligação, migração, proliferação e diferenciação de células endoteliais, células epiteliais e fibroblastos e por participarem ativamente do processo de reparo tecidual. Dessa forma, essas moléculas bioativas podem ser usadas para melhorar o processo de reparo em diversos órgãos e tecidos, embora a sua eficácia não tenha sido completamente comprovada cientificamente e necessite de mais estudos (THEORET, 2008).

Outro tipo de terapia utilizada na fase fibroblástica é a chamada 'terapia baseada em implantes', em que vários materiais naturais ou sintéticos são utilizados para estimular o crescimento e a migração de células mesenquimais, especialmente em feridas crônicas e que não se curam. Alguns desses materiais, como membranas de colágeno e enxertos de pele, têm sido testados em cavalos e o seu uso tem limitado o desenvolvimento do tecido de granulação exuberante e acelerado a cicatrização (THEORET, 2008). Os enxertos de pele são uma boa opção em casos onde há granulação saudável no leito da ferida, mas algum outro impedimento para a epitelização. Eles têm efeito inibitório na síntese do colágeno, nas células endoteliais, no crescimento de fibroblastos e na atividade sintética dos fibroblastos dermais, além de estimular a proliferação e migração das células epiteliais (GREENHALGH, 1998). Essa alternativa de tratamento será abordada em detalhes posteriormente neste trabalho.

Durante a fase de remodelamento é desejado um alto nível de contração da ferida. Nessa fase, as forças de tensão locais aumentam, fazendo com que a ferida diminua de tamanho e melhore a sua aparência (WILMINK, 2004). A contração é resultado da ação de fibroblastos especializados (miofibroblastos) e a sua ação depende das condições teciduais locais e da capacidade de contração inata das células. A diferenciação dessas células contráteis é regulada principalmente pelo fator de crescimento transformador $\beta-1$, fibronectina (componente da matriz extracelular) e pela presença de tensão mecânica. $\mathrm{Na}$ espécie equina, em razão da maior fixação da pele nos membros distais, a contração e a retração das feridas possuem um padrão alterado. O objetivo terapêutico durante essa fase deve ser aumentar a atividade dos miofibroblastos, para acelerar o fechamento da ferida. Uma vez que esse objetivo é alcançado, essas células devem ser eliminadas, pois sintetizam altos níveis de componentes da matriz extracelular e de metaloproteinases, que levam à cicatriz excessiva e prejuízo funcional ao órgão afetado (DESMOULIERE, 2005).

\section{ENXERTOS DE PELE}

Os enxertos de pele são uma boa alternativa para o tratamento de feridas de pele em equinos, especialmente aquelas em membros distais. $O$ seu uso pode melhorar o resultado final da cicatrização, tanto em relação ao tempo, quanto em 
relação aos resultados cosméticos e funcionais (BRISTOL, 2005), pois diminuem a superfície da granulação e estimulam a contração da ferida, acelerando o processo de reparo (DAHLGREN, 2009). Os enxertos são indicados em feridas extensas, com grande perda tecidual e pele insuficiente para que ocorra o fechamento adequado, e em feridas com desenvolvimento de tecido de granulação exuberante e consequente falha na contração, o que pode resultar em contratura. A contratura é caracterizada pela perda da elasticidade e da função normal de determinada estrutura, devido à contração excessiva da ferida, que geralmente acontece em regiões próximas a orifícios corpóreos ou articulações (BRISTOL, 2005).

Os enxertos devem ser realizados em áreas com suprimento sanguíneo adequado e livres de infecção. Contagem bacteriana superior a $10^{5}$ bactérias por grama de tecido pode levar a falhas na enxertia, pois algumas espécies de bactérias estimulam a produção de grande quantidade de exsudato, que pode deslocar fisicamente os enxertos e, ainda, outras espécies produzem enzimas proteolíticas que fazem a digestão da fibrina, que segura provisoriamente os enxertos no local (SCHUMACHER, 2012). Os cuidados pós-operatórios são primordiais para o sucesso do procedimento. Deve ser feito monitoramento rigoroso para sinais de infecção, debridamento ou tratamento tópico em tecido de granulação que continua a proliferar e uso adequado de bandagens e curativos (BRISTOL, 2005).

\section{Fisiologia e abordagem clínica dos enxertos de pele}

O primeiro obstáculo para o sucesso dos enxertos de pele é a dificuldade de aderência dos fragmentos no leito da ferida. Nos primeiros dias após o implante, essa aderência é feita pela fibrina do sítio recipiente, que se liga ao colágeno exposto do enxerto, formando uma ligação fraca (SCHUMACHER, 2012). Inicialmente os enxertos são nutridos pela embebição plasmática, evento pelo qual o plasma é passivamente absorvido pela ação dos capilares para o interior do lúmen exposto dos vasos dos enxertos. Durante a embebição plasmática, que dura cerca de 48 horas, o enxerto não tem suprimento sanguíneo próprio, a tensão de oxigênio cai e a atividade mitótica de suas células diminui. $O$ enxerto se torna edematoso e permanece assim até que ocorra a revascularização (VISTNES, 1997). Essa ligação fibrinosa é facilmente rompida por excesso de mobilidade ou destruição enzimática bacteriana. Os fibroblastos infiltram o local do enxerto cerca de 72 horas após o implante e começam a produzir adesão fibrosa mais consistente (SCHUMACHER, 2012). Também nesse período novos capilares da ferida atravessam a matriz fibrinosa e se anastomosam com os capilares do enxerto. A revascularização completa acontece por volta de cinco dias e a circulação linfática em sete dias (CONVERSE, 1975).

A epiderme dos enxertos pode sofrer necrose em algumas áreas, devido à falta de suprimento sanguíneo adequado nos primeiros dias. Nesses pontos a derme exposta se assemelha à granulação. Em humanos que recebem enxertos de espessura parcial, a inervação é restabelecida e a sensibilidade retorna em cerca de sete a nove semanas, mas de forma incompleta. Há relatos de que esses pacientes podem desenvolver hiperestesia e cavalos apresentam condição semelhante, demonstrada por automutilação em áreas enxertadas (HOGLE , 1959; FLOWERS, 1970).

Alguns fatores são imprescindíveis para que haja a aderência dos enxertos no leito da ferida. O sítio recipiente deve ter bom suprimento sanguíneo, sendo assim, feridas com exposição óssea, tendínea ou ligamentar precisam granular antes da realização do enxerto. Em casos de exposição óssea, é 
recomendada a realização de radiografia para identificação de possível sequestro ósseo, o que seria uma causa de falha na cicatrização. A radiografia, juntamente com a ultrassonografia, também é indicada quando existem pontos de drenagem que devem ser investigados, pois feridas infeccionadas não são boas candidatas aos enxertos, uma vez que as bactérias consomem nutrientes necessários para os enxertos e fazem digestão enzimática da fibrina (BRISTOL, 2005).

Quando a infecção é detectada, deve ser tratada imediatamente. Os antibióticos tópicos são mais eficazes que os sistêmicos, que geralmente não atingem a concentração terapêutica suficiente no interior e na superfície do tecido de granulação, pois a fibrina presente na base da granulação não permite a adequada penetração do fármaco (ROBSON, 1974). As feridas devem ser mantidas limpas e com bandagens enquanto a fibroplasia acontece, até que a granulação quase atinja o nível da pele adjacente (BRISTOL, 2005).

Quando há tecido de granulação exuberante, ele deve ser excisado até que fique abaixo da superfície da pele adjacente e deve ser realizada bandagem compressiva para controlar a hemorragia. Nesse caso, os enxertos devem ser realizados no dia seguinte. A granulação ideal para realização da enxertia deve ser firme, lisa, rósea e vascularizada, com poucas fissuras, além de não sangrar facilmente e produzir secreção fluida, sero-sanguinolenta ou levemente purulenta. As feridas extremamente crônicas possuem um leito fibroso com suprimento sanguíneo pobre e a excisão do tecido de granulação deve ser um pouco mais profunda. Os enxertos devem ser realizados após o preenchimento da ferida por granulação nova e saudável. Nos dois casos citados, no momento da realização dos implantes, qualquer hemorragia deve ser controlada, pois o sangramento pode deslocar os fragmentos de pele enxertados na granulação (BRISTOL, 2005).

\section{Classificação e tipos de enxertos}

Os enxertos de pele podem ser classificados de acordo com a espessura do tecido e com a relação doador - receptor. De acordo com a espessura, podem ser de espessura parcial, que são aqueles que contêm epiderme e uma espessura variável de derme; espessura parcial fina, que não contêm estruturas anexas, como raízes de pelo, e resultam em áreas epitelizadas sem pelo; espessura total, que contêm epiderme e espessura total da derme, sem o tecido subcutâneo subjacente e resultam em melhor resultado cosmético, devido ao crescimento dos pelos; e compostos, que contêm epiderme, derme e uma profundidade variável de tecido subjacente, podendo incluir gordura, músculo, cartilagem e outras estruturas (BRISTOL, 2005).

De acordo coma relação doador - receptor, os enxertos de pele podem ser classificados em autoenxertos, que são aqueles realizados no mesmo indivíduo; isoenxertos, que são realizados entre gêmeos idênticos; aloenxertos, que são realizados entre indivíduos diferentes da mesma espécie e xenoenxertos, que são realizados entre indivíduos de espécies diferentes. Os autoenxertos são os mais comuns na espécie equina (BRISTOL, 2005) e têm maior taxa de aceitação por induzirem menor resposta imune (GOMEZ et al., 2004).

Existem dois tipos principais de enxertos de pele: os enxertos em pedículo e os enxertos livres. Os enxertos em pedículo são de espessura total e se caracterizam por permanecerem ligados ao sítio doador por um pedículo vascular e, dessa forma, não dependerem da vascularização do sítio recipiente para sobreviver. Esse tipo de enxerto tem bom resultado cosmético, pois é composto por todas as camadas da pele, porém não é muito utilizado em equinos devido à dificuldade em 
mobilizar a quantidade adequada de tecido para a sua realização (WILSON, 1990). Já nos enxertos livres, a porção de pele colhida é destacada de sua fonte vascular e recolocada em uma ferida em outro ponto do corpo do indivíduo, onde deve criar uma nova conexão vascular para sobreviver (MAY, 1991). Esse tipo de enxerto é mais utilizado na clínica equina, devido à natureza inelástica da pele dos cavalos e à falta de pele adjacente móvel em feridas de extremidades de membros (DAHLGREN, 2009).

Os principais tipos de enxertos livres são: em ilha, que são os enxertos do tipo pinch, punch e em túnel, e os enxertos em folha ou camada. Os enxertos em ilha são caracterizados por pequenos fragmentos de pele de espessura total ou parcial, que são colhidos do sítio doador e colocados na granulação, produzindo, posteriormente, um halo de epiderme à sua volta. Já os enxertos em folha são caracterizados por sessões grandes de pele, também de espessura total ou parcial, que são colhidas do sítio doador e aplicadas em uma peça grande e intacta na granulação. A escolha do melhor tipo de enxerto deve ser baseada no tamanho e na localização da ferida, no resultado cosmético esperado, nos custos do tratamento, no equipamento disponível e na experiência do profissional. Os principais tipos de enxertos serão abordados a seguir (DAHLGREN, 2009).

\section{a) Enxertos do tipo pinch}

Os enxertos do tipo pinch são feitos através do beliscamento de uma pequena porção de pele com agulha fina e de sua retirada com o uso de lâmina de bisturi. Devido à maneira pela qual são obtidos, esses fragmentos de pele são de espessura parcial fina na periferia e aumentam a sua espessura em direção ao centro, onde chegam à espessura total. Essa variação faz com que o crescimento dos pelos também seja variável nesse tipo de enxerto (BRISTOL, 2005). O resultado desse tipo de colheita é um fragmento de pele em círculo ou elipse, de cerca de três milímetros de diâmetro (DAHLGREN, 2009).

Uma lâmina de bisturi no 15 é usada para criação de pequenos bolsos na granulação que irá receber os fragmentos de pele colhidos (FIGURA 2) (BRISTOL, 2005). São feitas linhas de bolsos com distância de um centímetro entre eles. Os fragmentos colhidos no sítio doador são introduzidos nesses bolsos, levando em consideração a orientação do crescimento dos pelos, para atingir um melhor resultado cosmético (DAHLGREN, 2009).

Uma a duas semanas após a enxertia, os fragmentos implantados começam a aparecer como pontos escuros no leito da granulação. Esse tipo de enxerto tem como vantagens a possibilidade de poder ser realizado com o animal apenas sob sedação e em posição quadrupedal, e, como os outros enxertos em ilha, a falha na aceitação de um fragmento não prejudica os demais (DAHLGREN, 2009). A taxa de sobrevivência desse tipo de enxerto é de 60\% a 70\% (SCHUMACHER, 2012). 
FIGURA 2 - Enxerto do tipo pinch sendo realizado em ferida em região proximal da canela de membro pélvico de um equino.

Fonte: Setor de Grandes Animais, HV/UFG.

\section{b) Enxertos do tipo punch}

Os enxertos do tipo punch são similiares aos do tipo pinch, mas são obtidos com o uso de um punch de biopsia e são de espessura total. O punch é rotacionado até que a espessura total da pele seja penetrada. Uma borda do fragmento é levantada com pinça e uma lâmina de bisturi no 15 ou tesoura Metzenbaum são utilizadas para retirar o enxerto. Os fragmentos devem ser colhidos com um centímetro de distância entre eles, para melhorar o resultado cosmético do sítio doador. Os locais das colheitas podem ser suturados ou não (DAHLGREN, 
2009). Após a colheita dos fragmentos de pele (FIGURA 3), é feita a retirada do tecido subcutâneo adjacente, que pode atrapalhar na revascularização dos enxertos (BRISTOL, 2005).

Um punch de menor calibre é usado para remover os plugs de tecido de granulação do leito da ferida ou sítio recipiente, onde serão colocados os fragmentos colhidos anteriormente (BRISTOL, 2005). Esses orifícios devem ser criados com cerca de seis a oito milímetros de distância entre eles e em relação às margens da ferida e swabs devem ser colocados em cada um deles, para controlar a hemorragia, que pode ser prejudicial para a aderência dos enxertos (FIGURA 4). Um halo de epitélio róseo pode ser detectado ao redor dos fragmentos de pele implantados cerca de três a quatro semanas após a enxertia. Em 42 a 56 dias os pelos começam a crescer (DAHLGREN, 2009). Esse tipo de enxerto tem um resultado cosmético melhor quando é considerada a direção do pelo no momento da sua colocação no leito da ferida (BRISTOL, 2005).

FIGURA 3 - Fragmentos de pele sendo colhidos da região do pescoço de um equino, abaixo da crina, com punch de biópsia.

Fonte: Setor de Grandes Animais, HV/UFG. 




FIGURA 4 - Sítio recipiente de enxertos do tipo punch em região de garupa de um equino. Swabs são colocados nos orifícios criados para controlar a hemorragia até que os fragmentos de pele sejam implantados.

\section{c) Enxertos do tipo túnel}

Fonte: Setor de Grandes Animais, HV/UFG.

Os enxertos em tiras ou do tipo túnel podem ser de espessura parcial ou de espessura total. Os de espessura parcial são obtidos com o uso de dermátomo. Já os de espessura total são obtidos através da injeção subcutânea de lidocaína ou solução salina, de forma a criar pápulas lineares de dois a três centímetros de largura e um pouco mais compridas que a ferida. Uma pinça intestinal reta é usada para auxiliar na retirada da porção de pele que foi erguida pela pápula (DAHLGREN, 2009). A partir desse fragmento de pele são obtidas tiras de dois milímetros de largura, que serão enxertadas na granulação, e é feita a retirada do tecido subcutâneo adjacente (SCHUMACHER, 2012).

O enxerto, então, é colocado em uma espécie de túnel criado na granulação do sítio recipiente, com profundidade de seis milímetros. A derme da tira de pele enxertada deve estar em contato com a superfície da ferida. As tiras devem ser colocadas paralelas umas às outras, com dois centímetros de distância entre elas, ao longo do comprimento da ferida e as suas extremidades devem ser suturadas na pele. Se esse tipo de enxerto for realizado em membros distais, pode ser feito torniquete para diminuir a hemorragia e melhorar a visualização. $O$ tecido de granulação sobre as tiras do enxerto deve ser removido ao nível da pele enxertada em seis a dez dias após o procedimento e deve ser realizada bandagem, assim como nos outros tipos (SCHUMACHER, 2012).

A epitelização deve estar completa em duas a quatro semanas (SCHUMACHER, 2012). A desvantagem desse método reside no fato de que pode existir algum ponto de drenagem ou infecção abaixo do enxerto, o que prejudica a sua captação de nutrientes (BRISTOL, 2005). Apesar de ser menos comum na clínica de equinos, esse tipo de enxerto é muito indicado para áreas com grande mobilidade, como carpo e tarso, e áreas em que é difícil colocar bandagem (DAHLGREN, 2009). 


\section{d) Enxertos em folha ou camada e enxertos em malha}

Em geral, na clínica de equinos, as feridas têm uma extensão maior do que os enxertos obtidos. Dessa forma, é comum usar técnicas de expansão dos enxertos em folha, criando fenestras ou malhas, para que se permita cobrir uma área muito maior da ferida. O procedimento pode ser realizado com o animal em pé, mas é preferível que se faça sob anestesia geral. O sítio doador deve ser uma área ampla e plana por onde o dermátomo, usado para a colheita da sessão de pele, deslize com facilidade, de preferência o abdômen ventral. $O$ tamanho do fragmento a ser colhido é determinado pelo tamanho da ferida, pois a expansão aumenta significativamente a sua largura, mas não há muito ganho em comprimento. As bordas do enxerto podem ultrapassar as margens da ferida e devem ser suturadas. A orientação do crescimento dos pelos também deve ser considerada nesse tipo de enxerto. A expansão em malha pode ser feita a mão ou com expansores comerciais.

Além da possibilidade de cobrir feridas mais extensas, esse método tem como vantagem a presença de orifícios por onde pode haver drenagem de seroma, sangue ou exsudato e que permite o contato de antimicrobianos tópicos com o leito da ferida, o que pode ser importante para o controle de infecções.

\section{Preparação do sítio doador e do sítio recipiente}

Enquanto os enxertos em malha são recomendados para cobertura de grandes defeitos, os enxertos em tiras propiciam um melhor resultado cosmético e os dos tipos pinch e punch são os de execução mais simples. O sucesso de qualquer um deles depende da preparação adequada dos sítios doador e recipiente e de um pós-operatório cuidadoso (BRISTOL, 2005).

O sítio doador deve ser um local onde a cicatriz é cosmeticamente aceitável. As regiões mais adequadas são o peitoral, o pescoço abaixo da crina, o abdômen lateral e a região lombar. O local escolhido deve ter espessura e flexibilidade apropriadas de acordo com o tipo de enxerto que será realizado. A região peitoral, que possui pele mais flexível, é mais indicada para enxertos do tipo pinch e em folha, enquanto a região lombar, que possui pele mais firme, pode ser uma boa opção para enxertos do tipo punch (DAHLGREN, 2009).

Devem ser realizadas tricotomia e antissepsia rigorosa. É preferível que a tricotomia seja realizada com lâmina de máquina de tosa $n^{\circ}$ 40, para que a direção do crescimento do pelo seja preservada. Na maioria dos casos, a colheita dos fragmentos pode ser realizada com o cavalo em posição quadrupedal, sob sedação. Recomenda-se que esse procedimento seja feito antes da preparação do sítio recipiente, mas não com um intervalo muito grande, para que se mantenha a saúde dos enxertos. Os fragmentos colhidos devem ser mantidos em gaze umedecida com solução salina, para que não ressequem e podem ser armazenados refrigerados, também em solução salina ou ringer com lactato, para uso semanas após a colheita (DAHLGREN, 2009).

O sítio recipiente deve apresentar margem de epitélio novo, o que indica que a granulação está saudável o suficiente para receber o enxerto (DAHLGREN, 2009). Quando a granulação está excedente, deve ser retirada. Esse procedimento pode ser realizado com o animal em pé e até sem sedação, uma vez que esse tecidoé pobremente inervado. A depender da qualidade do tecido de granulação presente, a excisão deve ser realizada dias ou até semanas antes da enxertia. Antimicrobianos tópicos podem ser aplicados, em caso de feridas infectadas (SCHUMACHER, 2012). 


\section{Cuidados pós-operatórios}

Após a realização dos enxertos deve ser realizado curativo com material não-aderente, pomadas antimicrobianas e colocação de bandagem. A bandagem é de extrema importância, pois além de proteger os enxertos e mantê-los no lugar, ela funciona como método para hemostasia e mantém o ambiente da ferida úmido, o que é um estímulo para a epitelização (FIGURA 5). O tipo de bandagem depende do tipo de enxerto e da sua localização (DAHLGREN, 2009).

A imobilização é necessária quando a ferida é localizada em regiões articulares, para evitar a remoção mecânica dos enxertos. Embora alguns autores recomendem a troca diária das bandagens, essa prática também pode levar ao deslocamento dos enxertos, que não estão completamente aderidos nos primeiros dias após a cirurgia (SCHUMACHER, 2012). Dessa forma, nas primeiras trocas o animal deve ser sedado, para evitar que se mexa inadvertidamente e tire os enxertos do lugar (DAHLGREN, 2009). Quando a imobilização é feita com gesso, esse pode ser deixado por 10 a 14 dias, que é quando passa a existir ligação fibrosa e vascular entre os enxertos e o leito da ferida (SCHUMACHER, 2012).



CONSIDERAÇÕES FINAIS 
Os ferimentos cutâneos são ocorrência muito comum na clínica de equinos e podem levar a importantes perdas funcionais e econômicas, como tempo prolongado de recuperação, custos altos com tratamentos diversos e, até mesmo, a inutilização do animal, principalmente devido à claudicação persistente. O processo de cicatrização apresenta particularidades nessa espécie, especialmente nas feridas dos membros distais, que apresentam maior predisposição a se tornarem crônicas e a apresentarem tecido de granulação exuberante.

Existe uma variedade de produtos e tratamentos que podem ajudar na cicatrização de feridas de equinos, porém é de extrema importância que se tenha conhecimento a respeito das fases do processo de cicatrização e da anatomia da região acometida. Esse conhecimento possibilita a escolha do protocolo de tratamento mais adequado, o que minimiza a chance do insucesso.

Os enxertos de pele são uma boa opção de tratamento para feridas extensas, com grande perda tecidual e que se tornaram crônicas. Existem vários tipos e várias técnicas de enxertia e a maioria delas é de baixo custo e de fácil execução, o que justificaria o seu maior uso pelos veterinários de campo e também dentro dos centros clínicos, como o próprio Hospital Veterinário da Universidade Federal de Goiás.

O médico veterinário de equinos deve saber reconhecer as estruturas comprometidas pela lesão, a fase da cicatrização em que a ferida se encontra e se há algum atraso nesse processo. Dessa forma, será possível escolher a terapia indicada, de acordo com o tipo de ferida, a sua localização, além da resposta individual do animal e o investimento e manejo disponíveis. Essa decisão pode ser a diferença entre o retorno do animal para suas atividades atléticas e a claudicação crônica ou eutanásia.

\section{REFERÊNCIAS}

BAXTER, G.M. Integument. In: COLAHAN, P.T; MAYHEW, I.G; MERRITT, A.M; MOORE, J.N (Eds.) Equine medicine and surgery. 5 ed. St. Louis: Mosby, p.17881946, 1999.

BERTONE, A. Principles of wound healing. Veterinary Clinics of North America: Equine Practice, v.5, n.3, p. 449-63, 1989. Disponível em: <https://www.ncbi.nlm.nih.gov/pubmed/2691024>. Acesso em: 12 mar. 2017.

BODNER, N.S; KISS-BURIS, S.T; BURIS, L. Novel soft steroids: effects on cell growth in vitro and on wound healing in the mouse. Steroids, v.58, n.8, p.434-9, 1991. Disponível em: <http://doi.org/10.1016/0039-128X(91)90032-Q>. Acesso em: 12 mar. 2017.

BRISTOL, D.G. Skin grafts and skin flaps in the horse. Veterinary Clinics of North America: Equine Practice. v. 21. n.1, p. 125-144, 2005. Doi: 10.1016/j.cveq.2004.11.007.

CASTON, S.S. Wound care in horses. Veterinary Clinics of North America: Equine Practice, v.28, p.83-100, 2012. Disponível em: <http://dx.doi.org/10.1016/j.cveq.2012.01.001 >. Acesso em: 12 mar. 2017.

COCHRANE, C.A; PAIN, R; KNOTTENBELT, D.C. In-vitro wound contraction in the horse: differences between body and limb wounds. Wounds, v.15, n.6, p. 175-181, 
2003. Disponível em: < http://www.medscape.com/viewarticle/457928>. Acesso em: 12 mar. 2017.

CONVERSE, J.M; SMAHEL, J; BALLANTYNE, D.L. JR; HARPER, A.D. Inosculation of vessels of skin graft and host bed: a fortuitous encounter. British Journal of Plastic Surgery. v.28. n.4, p. 274-282, oct. 1975. Disponível em: <https://www.ncbi.nlm.nih.gov/pubmed/1104028>. Acesso em: 12 mar. 2017.

DAHLGREN, L.A. Skin grafting. In: ROBINSON, E.N; SPRAYBERRY, K.A. (Eds.) Current Therapy in Equine Medicine. 6 ed. St. Louis: Saunders, p. 721-726, 2009.

DART, A.J; DOWLING, B.A; SMITH, C.L. Topical treatments in equine wound management. Veterinary Clinics of North America: Equine Practice. New South Wales. v.21. n.1, p. 77-79, apr. 2005. Disponível em: <http://dx.doi.org/10.1016/j.cveq.2004.11.003>. Acesso em: 12 mar. 2017.

DESMOULIERE, A; CHAPONNIER, C; GABBIANI, G. Tissue repair, contraction, and the myofibroblast. Wound Repair Regen. Bordeaux, v.23. n.7, p. 7-12, jan. 2005. Doi: 10.1111/j.1067-1927.2005.130102.x.

EDWARDS, R; HARDING, K.G. Bacteria and wound healing. Current Opinion in Infectious Diseases, v.17, p.91-96, 2004. Doi: 10.1097/00001432-20040400000004.

FLOWERS, R.S. Unexpected postoperative problems in skin grafting. Surgical Clinics of North America. California, v. 50. n.2, p. 439-456, april. 1970. Disponível em: <https://doi.org/10.1016/S0039-6109(16)39092-2>. Acesso em: 12 mar. 2017.

GIFT, L.J; DEBOWES, R.M. Wounds associated with osseous sequestration and penetrating foreign bodies. Veterinary Clinics of North America: Equine Practice, v.5, n.3, p.695-708, 1989. Disponível em: <https://www.ncbi.nlm.nih.gov/pubmed/2691039 >. Acesso em: 12 mar. 2017.

GOMEZ, J.H. et al. Effects of three biological dressings on healing of cutaneous wounds on the limbs of horses. Canadian Journal of Veterinary Research. v.68. n.1, p. 49-55, jan. 2004. Disponível em: < https://www.ncbi.nlm.nih.gov/pmc/articles/PMC1142129/>. Acesso em: 12 mar. 2017.

GREENHALGH, D.G. The role of apoptosis in wound healing. The International Journal of Biochemistry \& Cell Biology. Califoria, v.30. n.9, p.1019-1030, may. 1998. Disponível em: <https://www.ncbi.nlm.nih.gov/pubmed/9785465>. Acesso em: 12 mar. 2017.

HANSON, R.R. New concepts in the treatment of large avulsion wounds of the distal extremities. AAEP Proceedings. v.52, n.1, p. 281-299, 2006. Disponível em: < https://www.cabdirect.org/cabdirect/abstract/20073084995 >. Acesso em: 12 mar. 2017.

HOGLE, R.B; KINGREY, W; JENSEN, E.C. Skin grafting in the horse. Journal of the American Veterinary Medical Association. v.135. n.3, p.165-170, aug. 1959. Disponível em: <https://www.ncbi.nlm.nih.gov/pubmed/13672873>. Acesso em: 12 mar. 2017. 
HOWARD, R.D; STASHAK, T.S; BAXTER, G.M. Evaluation of occlusive dressings for management of full-thickness excisional wounds on the distal portion of the limbs of horses. American Journal of Veterinary Research., v. 54. n.12, p. 2150-4, dec. 1993. Disponível em: < https://www.ncbi.nlm.nih.gov/pubmed/8116952>. Acesso em: 12 mar. 2017.

JACOBS, K.A; LEACH, D.H; FRETZ, P.B. Comparative aspects of the healing of excisional wounds on the leg and body of horses. Veterinary Surgery Journal, v.13, n.2, p.83-90, 1984. Doi: 10.1111/j.1532-950X.1984.tb00765.x.

JONES, T.C; HUNT, R.D; KING, N.W. Patologia Veterinária. Tradução de NASCIMENTO, F.G. 6 ed. São Paulo: Manole, p.1415, 2000.

KNOTTENBELT, D.C. Handbook of equine wound management. 1 ed. Liverpool: Saunders, p.140, 2003.

LI, L; ZHANG, Y.P; KIRSNER, R.S. Angiogenesis in wound repair: angiogenic growth factors and the extracellular matrix. Microscopy Research and Technique, v.1, n.60, p. 107-14, 2003. Doi: 10.1002/jemt.10249.

LINEAWEAVER, W; HOWARD, R; SOUEY, D. Topical antimicrobial toxicity. Archives of surgery, v.120, p.267-270, 1985. Disponível em: <https://www.ncbi.nlm.nih.gov/pubmed/3970664>. Acesso em: 12 mar. 2017.

MAY, S. The effects of biological wound dressings on the healing process. Clinical Materials. v.8. n.3, p. 243-249, 1991. Disponível em: <https://doi.org/10.1016/02676605(91)90037-G>. Acesso em: 12 mar. 2017.

MOY, L.S. Management of acute wounds. Dermatologic Clinics, v.11, n.4, p. 75976, 1993. Doi: 10.1016/j.suc.2009.03.005.

ROBSON, M.C; EDSTOM, L.E; KRIZEK. T.J. The efficacy of systemic antibiotics in the treatment of granulating wounds. Journal of Surgical Research. v.16. n.4, p. 299-306, april. 1974. Disponível em: <https://doi.org/10.1016/0022-4804(74)90046-8>. Acesso em: 12 mar. 2017.

RODEHEAVER, G; BELLAMY, W; KODY, M. Bactericidal activity and toxicity of iodine containing solutions in wounds. Archives of surgery, v.117, n.2, p. 181-186, 1982. Doi: 10.1001/archsurg.1982.01380260051009.

SCHUMACHER, J. Skin grafting. In: AUER, J.A; STICK, J.A. Equine Surgery. 4.ed. Missouri: Saunders, p. 285-305, 2012.

SCHUMACHER, J; WILMINK, J.M. Free skin grafting. In: STASHAK, T.S; THEORET, C.L. Equine wound management. 2.ed. Lowa: Wiley-Blackwell, p. 509542, 2008.

SINGER, A.J; CLARK, R.A. Cutaneous wound healing. New England Journal of Medicine, v.10, n.341, p.738-746, 1999. Doi: 10.1056/NEJM199909023411006.

STOTTS, N.A; WIPKE-TEVIS,D.D. Co-factors in impaired wound healing. In: KRASNER, D.L; RODEHEAVER, G.T; SIBBALD, R.G. (Eds.) Chronic wound care: a source book for healthcare professionals. 3 ed. Wayne: HMP Communications, 
p. 265-73, 2001. Disponível em: < https://www.ncbi.nlm.nih.gov/pubmed/8703295> Acesso em: 12 mar. 2017.

TARNOW, P; AGREN, M; STEENFOS, H; JANSSON, J.O. Topical zinc oxide treatment increases endogenous gene expression of insulin-like growth factor-1 in granulation tissue from porcine wounds. Journal of Plastic Surgery and Hand Surgery, v.28, p.255-259, 1994. Disponível em: $<$ http://dx.doi.org/10.3109/02844319409022008>. Acesso em: 12 mar. 2017.

THEORET, C.L. Physiology of wound healing. In: STASHAK, T.S; THEORET, C.L. Equine wound management. 2.ed. Lowa: Wiley-Blackwell, p. 5-28, 2008.

THEORET, C.L. The pathophysiology of wound repair. Veterinary Clinics of North America: Equine Practice, v.21, p.1-13, 2005. Doi: 10.1016/j.cveq.2004.11.001.

THEORET, C.L. Wound repair: Problems in the horse and innovative solutions. In: STASHAK, T.S; THEORET, C.L. Equine wound management. 2.ed. Lowa: WileyBlackwell, p. 47-68, 2008. Doi: 10.1053/j.ctep.2004.08.010.

VISTNES, L.M. Grafting of skin. Surgical Clinics of North America. California, v.57. n.5, p.939-960, oct. 1977. Doi: https://doi.org/10.1016/S0039-6109(16)41335-6.

WILMINK, J.M; VAN WEEREN, P.R. Treatment of exuberant granulation tissue. Clinical Techniques Equine Practice. Netherlands, v. 3. n. 2, p. 141-47, june. 2004. Doi:10.1053/j.ctep.2004.08.012.

WILMINK, J.M; WEEREN, P.R. Second-intention repair in the horse and pony and management of exuberant granulation tissue. Veterinary Clinics of North America: Equine Practice, v.21, n.1, p.15-32, 2005. Doi: 10.1016/j.cveq.2004.11.014.

WILSON, D.G. Applications of skin grafting in large animals. Problems in Veterinary Medicine Journal. v.2. n.3, p.442-462, sep. 1990. Disponível em: < https://www.ncbi.nlm.nih.gov/pubmed/2134606>. Acesso em: 12 mar. 2017.

WISON, D.A. New and innovative approaches to wound closure. In: STASHAK, T.S; THEORET C.L. Equine wound management. 2.ed. Lowa: Wiley-Blackwell, p. 225237, 2008. 